\title{
RIBUIÇÕES DA NOVA SUDENE PARA O DESENVOLVIMENTO DO NORDESTE
}

\author{
Egon Bianchini Calderari* \\ Caroline Pereira Gomes** \\ Fabiane de Oliveira Beatrice**** \\ Ricardo Lobato Torres****
}

\begin{abstract}
Resumo
Este artigo faz uma avaliação preliminar das contribuições da nova Sudene para o desenvolvimento do Nordeste, com base nas diretrizes políticas estabelecidas a partir de sua recriação, em 2007. Para o estudo, foi realizada uma pesquisa bibliográfica e documental para o mapeamento das diretrizes e prioridades da Sudene. Foi realizado ainda uma pesquisa de dados estatísticos secundários para analisar a evolução socioeconômica do Nordeste no período de 2007 a 2017. Para isso, foram utilizados os dados do PIB, do PIB per capita e do índice de Gini do IBGE, e do índice de desenvolvimento humano municipal da Firjan. Os resultados da pesquisa indicam que a Sudene recuperou sua importância estratégia na política do governo federal, como demonstra a instituição legal do alinhamento do Plano Regional de Desenvolvimento do Nordeste com o Plano Plurianual, com participação na elaboração do orçamento da União, a fim de garantir recursos para o desenvolvimento da região. Após uma década de sua recriação, é possível verificar avanços socioeconômicos, como o maior crescimento do PIB per capita no país, de 41,5\% entre 2007 e 2015, enquanto a média nacional foi de $29 \%$. Houve significativa melhoria no índice de desenvolvimento humano nas dimensões de saúde e de educação, acumulando no período uma variação de 55,7\% e 70,5\%, respectivamente. Entretanto, são ainda notáveis as limitações desse progresso, uma vez que o PIB per capita ainda é praticamente metade da média nacional e o Nordeste ainda apresenta o maior índice de desigualdade de renda do país.
\end{abstract}

Palavras-chave: Sudene. Nordeste. Desenvolvimento regional. Planejamento econômico. Políticas públicas.

\footnotetext{
* Mestrando do Programa de Pós-Graduação em Administração (PPGA/UTFPR). Universidade Tecnológica Federal do Paraná (UTFPR).

** Graduada em Administração (DAGEE/UTFPR).

*** Graduanda em Administração (DAGEE/UTFPR) e Graduada em Ciências Biológicas (UNIVERSIDADE POSITIVO).

**** Doutor em Economia da Indústria e da Tecnologia (UFRJ), Mestre em Economia (UFSC). Coordenador do Programa de PósGraduação em Planejamento e Governança Pública (PGP/UTFPR) e Professor do Programa de Pós-Graduação em Administração (PPGA/UTFPR).
} 


\section{Introdução}

Criada em 1959, pela Lei no 3.692, de 15 de dezembro de 1959, a Superintendência de Desenvolvimento do Nordeste (Sudene) foi uma autarquia idealizada para planejar e executar políticas para o desenvolvimento socioeconômico na já então região mais pobre e desigual do país. Subordinada diretamente à Presidência da República, a Sudene, em seus anos iniciais, ocupou um papel estratégico nos planos nacionais de desenvolvimento econômico (BRASIL, 1959).

Ao longo dos anos, porém, houve diversas mudanças institucionais em sua estrutura e, entre sucessos e insucessos, marcados por escândalos de corrupção, acabou por ser extinta em 2001, sendo transformada na Agência de Desenvolvimento do Nordeste (ADENE), um órgão meramente executor dos fundos constitucionais destinados à região (MASCARENHAS; LOURENÇO NETO, 2018).

Recriada em 2007, a nova Sudene ficou vinculada ao Ministério da Integração Nacional e ganhou uma série de atribuições e competências de planejamento em órgãos colegiados, tendo também uma participação ativa na formulação dos orçamentos da União (SILVA; ALMEIDA, 2011), recuperando seu protagonismo outrora buscado pelo seu idealizador, Celso Furtado, quando de sua instituição (FURTADO, 1959a).

Transcorrida pouco mais de uma década de sua criação, este artigo propõe, ainda que de forma preliminar, avaliar as formas de atuação da nova Sudene no planejamento do desenvolvimento regional do Nordeste e os resultados socioeconômicos obtidos até então.

O artigo está estruturado em mais quatro seções além desta introdução. $\mathrm{Na}$ próxima seção discute-se o desenvolvimento regional enquanto política pública, como fundamento teórico para análise do caso da Sudene. Na terceira descreve-se a metodologia da pesquisa. A quarta e a quinta seção discutem, respectivamente, as formas de atuação da Sudene (diretrizes e instrumentos de política) e os resultados socioeconômicos verificados na região Nordeste no período de 2007 a 2017. Por fim, a sexta e última seção traz as conclusões preliminares da pesquisa.

\section{Políticas públicas e desenvolvimento regional}

O campo de estudos das políticas públicas é complexo, constituído por contradições. A diversidade de abordagens e a pluralidade de conceitos são reflexos do que se encontra no campo empírico, onde a realidade manifestase de forma multifacetada, sendo perceptível observar grandes diferenças no modo em que as políticas públicas são constituídas e administradas em cada país. Da mesma forma que proporciona maiores dificuldades de 
síntese, a heterogeneidade da área permite também amplas opções, capazes de enriquecer o debate, além de proporcionar uma grande capacidade adaptativa prática ao não se ater a modelos únicos e/ou padronizados.

Para Dye (2011, p. 1), a política pública "é tudo o que os governos decidem ou não fazer”. Para o autor, as políticas públicas são capazes de regular o comportamento social, organizar a estrutura burocrática, distribuir benefícios e arrecadar impostos. Kraft e Furlong (2010) conceituam políticas públicas como sendo o que os funcionários públicos, que atuam dentro do governo, decidem ou não fazer sobre os problemas públicos. Estes problemas, originados de demandas sociais, ambientais ou econômicas, podem ser resolvidos pelo governo, pela iniciativa privada (cidadãos e empresas) ou pelo misto dos dois.

Dentre as principais preocupações dos governos, ao redor do globo, está a redução das disparidades inter-regionais. A atenção governamental dada aos problemas regionais é iniciada a partir das décadas de 50 e 60 na Europa, com a ascensão da economia regional como campo de estudos direcionado à compreensão e a redução das desigualdades (PINDER, 2017). Segundo Sousa (2008) e Araújo (1999), o grande objetivo das políticas regionais é proporcionar a redução sistemática das desigualdades regionais de forma a criar novas oportunidades socioeconômicas localizadas e promover maior competitividade às regiões subdesenvolvidas.

Para Celso Furtado (1959b) a concepção de desenvolvimento é propensa a criar desigualdades por meio de um processo de crescimento econômico direcionado à acumulação. Enquanto algumas regiões crescem e concentram recursos e tornam-se mais atrativas, outras sofrem em não se adaptar ao fenômeno, o que é capaz de gerar problemas culturais e estruturais que dificultam a formação de uma consciência nacional homogênea (FURTADO, 2014).

Segundo Cavalcante (2018), os problemas regionais brasileiros vêm sido discutidos frequentemente nas esferas pública e acadêmica desde pelo menos a segunda metade do século XX, principalmente no que tange as disparidades apresentadas entre as regiões Norte e Sul do país. Entre os anos de 1947 e 1961 houve um considerável agravamento das disparidades regionais no Brasil, decorrentes do processo de crescimento acelerado no pós-guerra e que se concentrou quase inteiramente no Centro-Sul com incentivos à industrialização e substituição das importações no país, pela maior vantagem locacional para o tipo de atividade manufatureira. Para Gumiero (2017), o diagnóstico feito para a situação do Nordeste foi de subdesenvolvimento, resultado de um atraso apresentado pela região em comparação as outras regiões do país.

As políticas desenvolvidas visando a superação das desigualdades da região Nordeste, segundo Gumiero (2017), passaram por 4 diferente fases: 
1) a consolidação do diagnóstico e das diretrizes para o desenvolvimento do Nordeste, materializado através da Operação Nordeste (1958-64); 2) O desenvolvimento de programas setoriais e de infraestrutura financiados através do Fundo de Investimentos do Nordeste (FINOR) (196584); 3) Um período de hiato político, estimulado pela influência das soluções neoliberais às economias em desenvolvimento e; 4) A retomada da perspectiva do Estado como indutor do desenvolvimento regional, consolidada com a elaboração do Plano Regional de Desenvolvimento do Nordeste (PRDNE) (2003-14).

O PRDNE (2011) consolidou o flexível planejamento estratégico estabelecido para Região Nordeste dentro de uma perspectiva desenvolvimentista, tendo como uma das premissas integrar verticalmente e horizontalmente entes dos três níveis do poder executivo. O objetivo principal do PRDNE (2011, p. 9) foi definido como "a inclusão social e a mobilização de todos os nordestinos como protagonistas de um processo de desenvolvimento que assegure a justiça social ao mesmo tempo em que valorize a identidade cultural nordestina e preserve os ativos ambientais da região".

O PRDNE é um desdobramento da Política Nacional de Desenvolvimento Regional (PNDR), instituído oficialmente no segundo mandato do Governo do Presidente Luiz Inácio Lula da Silva, através do Decreto no 6.047, de 22 de fevereiro de 2007. O objetivo principal instituído para o Plano foi a redução das desigualdades regionais, com a promoção da equidade e geração de oportunidades equivalentes aos habitantes das diversas regiões do país (BRASIL, 2007). Como coordenadora do PRDNE é nomeada a SUDENE, cujas competências de articulação e coordenação, reinstituídas em sua recriação, alinham-se diretamente com as proposições do plano.

\section{Sudene: Um breve Histórico}

A Sudene originalmente surgiu a partir do grupo de trabalho liderado por Celso Furtado, que buscou investigar os principais motivos pelos quais o Nordeste passava por dificuldades de desenvolvimento, tendo como objetivo principal a proposição de ações para o enfrentamento dos problemas apresentados pela região (OLIVEIRA, 2016).

Para Toledo (2013), em 1958, momento em que a região Nordeste enfrentava uma grave seca, que gerou efeitos catastróficos para a agricultura de subsistência local, ficou evidente que o governo havia elaborado um diagnóstico equivocado sobre os problemas socioeconômicos da região, de que a seca seria o principal problema a ser combatido na região. A estratégia adotada pelo governo central, a criação de açudes destinados à agricultura, 
foi colocada em prática pelo Departamento Nacional de Obras Contra as Secas (DOCS) no mesmo período e não se demonstrou eficaz (TOLEDO, 2013).

Enquanto a Superintendência esperava a aprovação do Congresso Nacional para o início de suas atividades, as propostas de Furtado começaram a serem executadas pela Coordenação de Desenvolvimento do Nordeste (CODENO), que seguiu os planos para o Nordeste que foram estabelecidos durante a gestão do presidente Juscelino Kubitscheck, em 1959, (MENDES, 2017). Para Souza (2006), a principal justificativa que respaldou o surgimento de uma autarquia independente para atuação orientada ao desenvolvimento da região Nordeste foi a ineficiência das práticas clássicas adotadas. A criação de um órgão com práticas mais flexíveis e que centralizasse as responsabilidades quanto a ações de planejamento e investimentos foi tida como fundamental para o estabelecimento de diretrizes desenvolvimentistas ao Nordeste (SOUZA, 2006).

Entretanto, do contrário com o que era esperado, desde sua criação a Sudene sofreu com as reações político-ideológicas das elites, que promoviam resistência às propostas planejadas. As pressões terminaram por limitar o trabalho do Grupo de Desenvolvimento, fazendo com que a autarquia atuasse com projetos em que enfrentava menor resistência para que assim suas ações não conflitassem com os interesses da elite (DINIZ, 2009).

Segundo Moreira (2003), diversas falhas apresentadas pela Sudene, como a ausência de fiscalização a projetos em andamento e a ingerência na liberação de recursos fizeram com que a credibilidade do órgão fosse arruinada. Os problemas estruturais apresentados pela Sudene motivaram a instauração de uma Comissão Parlamentar de Inquérito (CPI da Finor), que no ano de $2001 \mathrm{fez}$ diversas denúncias de corrupção que danificaram a base política do Governo no Congresso Nacional (CARVALHO, 2006). Fernando Henrique Cardoso, presidente durante o período de agravamento da crise institucional Sudene, decide extinguir a Superintendência, criando em seu lugar duas agências, a Agência de Desenvolvimento do Nordeste (Adene) e a Agência de Desenvolvimento da Amazônia (Ada), com fundos meramente orçamentários (TORRES, GOMES, BEATRICE; CALDERARI, 2019).

Em 2007, após um período de quase quatro anos de tramitação de projeto de lei no congresso, enviado pelo poder executivo, e pressões sociais encabeçadas pelo Movimento Acorda Nordeste (MANO), a Sudene é recriada com a Lei Complementar no 125 , de 3 de janeiro de 2007 (TORRES, et al. 2019). Segundo Silva e Almeida (2011), a Nova Sudene teria o objetivo de formular planos e propor diretrizes para o desenvolvimento do Nordeste, avaliando os impactos econômico e social da política empregada por ela. Segundo os autores, diferentemente da 
primeira, a Nova Sudene teria como diferenciais uma maior integração junto aos ministérios e órgãos governamentais que apoiam a região, além da possibilidade em realizar aportes financeiros em infraestrutura, capital humano e inovação.

\section{Métodos da pesquisa}

Para o presente estudo realizou-se uma pesquisa aplicada, de caráter descritivo, utilizando-se de uma abordagem do problema de pesquisa mista, com etapas qualitativas e quantitativas em busca da resolução do objetivo principal proposto. A primeira etapa foi composta por pesquisa bibliográfica, de natureza qualitativa, que teve como objetivo levantar os dos principais conceitos que circundam o tema, com base nas contribuições de livros e artigos encontrados em revistas cujo foco está direcionado ao desenvolvimento regional, e leis que instituem a Sudene como autarquia da República Federativa brasileira. Como complemento a esta etapa, realizouse uma pesquisa documental mediante consulta aos documentos e relatórios disponibilizados pela própria Sudene em sua página eletrônica institucional, em especial, o Plano Regional de Desenvolvimento do Nordeste (PRDNE), principal instrumento de atuação da SUDENE. É preciso ressaltar que no momento da consulta, apenas o PRDNE referente aos anos de 2012 a 2015 estava disponível na plataforma, não sendo possível acessar o documento referente ao primeiro quinquênio e nem aos dois anos posteriores.

A segunda etapa consistiu na avaliação do desempenho da Região Nordeste em relação as outras regiões no país a partir da recriação da Sudene. Para que sua realização fosse possível, selecionaram-se algumas variáveis socioeconômicas com vistas a comparar o desempenho das regiões do país, sendo elas: Produto Interno Bruto (PIB), PIB Per Capita, variação no pessoal ocupado assalariado nos grandes setores da economia e índice de Gini. Os dados foram obtidos pelo Sistema de Recuperação Automática (SIDRA), do pelo Instituto Brasileiro de Geografia e Estatística (IBGE), cuja base é disponibilizada online na internet com acesso livre.

Utilizou-se ainda, para avaliação do desempenho de indicadores socioeconômicos, o Índice Firjan de Desenvolvimento Municipal (IFDM), cujos dados foram obtidos através da base disponibilizada na página eletrônica da própria Federação das Indústrias do Rio de Janeiro (FIRJAN). O IFDM permite o acompanhamento anual do desenvolvimento socioeconômico dos munícipios brasileiros a partir de três eixos (Emprego e Renda, Educação e Saúde), tendo metodologia muito próxima àquela utilizada pelo Índice de Desenvolvimento Humano (IDH), baseada em uma escala que varia de 0 a 1 , em que os valores mais próximos de 1 indicam a existência de um maior desenvolvimento na região analisada. 
Para que fossem possíveis as análises da evolução do indicador a nível macrorregional, os indicadores obtidos para os municípios foram consolidados primeiramente no nível estadual e depois no nível regional, utilizando-se cálculos de média aritmética. O período de análise compreende os anos de 2005 a 2017, podendo variar em cada um dos indicadores adotados devido a disponibilidade dos dados presente nas bases utilizadas.

\section{As formas de atuação da nova Sudene}

$\mathrm{O}$ art. $3^{\circ}$ da Lei Complementar no 125/2007 estabelece que "A Sudene tem por finalidade promover o desenvolvimento includente e sustentável de sua área de atuação e a integração competitiva de base produtiva regional na economia nacional e internacional". Para que esses objetivos sejam alcançados, criou-se, como parte estrutural da Sudene, a Diretoria de Promoção do Desenvolvimento Sustentável.

Segundo o site da SUDENE (2018, p. 1), o FDNE tem como principal objetivo "assegurar recursos para a realização de investimentos na área de atuação da Sudene, em infraestrutura e serviços públicos e em empreendimentos produtivos com grande capacidade germinativa de novos negócios e novas atividades produtivas", o que o caracteriza como um importante instrumento destinado à promoção de áreas consideradas estratégicas para o desenvolvimento do país.

A autarquia conta com um Conselho Deliberativo, Diretoria Colegiada, Procuradoria Geral, vinculada à uma Ouvidora-geral da União, Auditoria Geral e Ouvidoria onde ocorrem reuniões trimestrais pela convocação do presidente do conselho e dentre os participantes das reuniões constam os governadores dos nove estados do Nordeste mais os representantes pelos estados do Espírito Santo e Minas Gerais (COSTA, 2016).

Segundo relatório disponibilizado pelo Movimento Acorda Nordeste (MANO), a Sudene concebeu em sua nova versão a criação de comitês para as entidades de créditos, recebendo assim suporte dos principais órgãos financiadores (Banco do Brasil, Banco do Nordeste do Brasil, Banco Nacional de Desenvolvimento Econômico e Social e Caixa Econômica Federal) para realização de análises de investimentos destinados ao Nordeste. Além disso, recebe apoio técnico dos principais órgãos de atuação no desenvolvimento do Nordeste como da Companhia Hidroelétrica do São Francisco, Companhia de Desenvolvimento dos Vales do São Francisco e do Parnaíba, Fundação Joaquim Nabuco, e Departamento Nacional de Obras Contra as Secas e o próprio Banco do Nordeste do Brasil, para a discussão de ideias e formulação de objetivos comuns com estas instituições (SILVA FILHO, 2008). 
Dentre as diretrizes gerais estabelecidas pela SUDENE para os anos de 2012 a 2015, destacam a redução das desigualdades sociais e regionais e a excelência na gestão para garantia da disponibilização de bens e serviços, que podem ser relacionadas aos indicadores socioeconômicos em propostas de avaliação (SUDENE,2018). O Quadro 1 dispõe as 4 diretrizes resumidas do PRDNE de 2012-2015.

Quadro 1 - Diretrizes estratégicas da Sudene

\begin{tabular}{|c|c|c|c|}
\hline $\begin{array}{l}\text { Dir. } 1 \text { - Promover a } \\
\text { competitividade sistêmica } \\
\text { da base produtiva do } \\
\text { Nordeste }\end{array}$ & $\begin{array}{l}\text { Dir. } 2 \text { - Universalizar } \\
\text { o acesso a ativos } \\
\text { estratégicos }\end{array}$ & $\begin{array}{l}\text { Dir. } 3 \text { - Promover a excelência } \\
\text { técnica e a qualidade da gestão } \\
\text { na Sudene }\end{array}$ & $\begin{array}{l}\text { Dir. } 4 \text { - Fortalecer a } \\
\text { imagem da Sudene }\end{array}$ \\
\hline $\begin{array}{l}\text { 1.1 Promover o aumento } \\
\text { da competitividade com o } \\
\text { fortalecimento da cadeia } \\
\text { produtiva; } \\
\text { 1.2 Fortalecer a infraestrutura da } \\
\text { região; } \\
\text { 1.3 Ampliar a aplicação } \\
\text { dos recursos dos fundos de } \\
\text { investimento; } \\
1.4 \text { Acrescentar a abordagem } \\
\text { regional nas políticas nacionais; } \\
\text { 1.5 Fortalecer a administração } \\
\text { pública. }\end{array}$ & $\begin{array}{l}\text { 2.1. Incentivar a } \\
\text { qualidade da educação; } \\
\text { 2.2. Propor soluções } \\
\text { viáveis ao semiárido; } \\
\text { 2.3. Propor a } \\
\text { sustentabilidade } \\
\text { regional; } \\
\text { 2.4. Incentivar a atuação } \\
\text { do sistema regional de } \\
\text { Defesa Civil. }\end{array}$ & $\begin{array}{l}\text { 3.1. Valorizar a modernização } \\
\text { da gestão e dos seus servidores; } \\
\text { 3.2. Garantir uma qualidade da } \\
\text { gestão de informações; } \\
\text { 3.3. Garantir uma modernização } \\
\text { das instalações internas. }\end{array}$ & $\begin{array}{l}\text { 4.1. Melhorar a } \\
\text { comunicação interna } \\
\text { e externa; } \\
\text { 4.2. Transformar } \\
\text { o colegiado da } \\
\text { Sudene em um } \\
\text { fórum de discussão } \\
\text { de ações estratégicas } \\
\text { a respeito do tema } \\
\text { de desenvolvimento } \\
\text { regional. }\end{array}$ \\
\hline
\end{tabular}

Fonte: Sudene (2018).

Nota: Adaptado pelos autores.

A sua relação com o seu meio de atuação vai muito além de geração de empregos ou oportunidades ficais para os pequenos negócios locais. Passa pela missão de fortalecer a região, dando base para que as pessoas consigam crescer, propondo-se a investir em qualificação e na excelência de gestão. É possível destacar também a preocupação da Superintendência quanto ao alcance de uma economia mais sustentável à região, ainda carente de recursos técnicos, além da proposição que busca o fortalecimento da sua imagem, com vistas a recuperar a credibilidade que fora perdida antes mesmo de sua extinção (MASCARENHAS; LOURENÇO NETO, 2018).

\section{Uma análise das transformações socioeconômicas do Nordeste:} 2007 a 2017

Na presente seção são expostas as análises realizadas sobre a evolução das variáveis selecionadas para avaliar a ocorrência das transformações socioeconômicas do Nordeste após a recriação da Sudene. Todos os dados foram condensados de forma a permitir a realização de análises comparativas entre as macrorregiões do país. Os indicadores econômicos PIB e PIB per 
capita foram deflacionados adotando o ano de 2007 como base. O recorte foi realizado tendo como referência o ano de 2007, marcado pela recriação da Sudene, com exceção do IFDM, cujo ano inicial incluído nas análises foi o de 2006, ano anterior a recriação da Sudene.

$\mathrm{Na}$ Tabela 1 estão expostos os valores do Produto Interno Bruto (PIB) do Brasil e das grandes regiões. É possível notar que, durante o período, a região do Sudeste foi a que apresentou o menor crescimento em seu PIB Real. Quando calculada a variação na participação das grandes regiões no PIB brasileiro, dentro do mesmo período de análise, percebese que enquanto as regiões do Nordeste e Centro-Oeste aumentaram sua participação no valor total de riqueza produzido no país, respectivamente de $13,03 \%$ e $8,56 \%$ para $14,15 \%$ e $9,67 \%$, a região Sudeste diminuiu sua participação de 57,36\% para 54,02\% do PIB entre os anos de 2007 a 2015.

Tabela 1 - PIB Real - Brasil e Grandes Regióes em mil R\$ (Período de 2007 a 2015)

\begin{tabular}{|c|c|c|c|c|c|c|}
\hline Ano & Brasil & Norte & Nordeste & Sudeste & Sul & Centro-Oeste \\
\hline 2007 & $\begin{array}{c}\mathrm{R} \$ \\
2.720 .262,95\end{array}$ & $\begin{array}{c}\mathrm{R} \$ \\
135.631,87\end{array}$ & $\begin{array}{c}\mathrm{R} \$ \\
354.392,34\end{array}$ & $\begin{array}{c}\mathrm{R} \$ \\
1.560 .365,10\end{array}$ & $\begin{array}{c}\mathrm{R} \$ \\
436.946,74\end{array}$ & $\begin{array}{c}\mathrm{R} \$ \\
232.926,91\end{array}$ \\
\hline 2008 & $\begin{array}{c}\mathrm{R} \$ \\
2.870 .675,80\end{array}$ & $\begin{array}{c}\mathrm{R} \$ \\
144.629,10\end{array}$ & $\begin{array}{c}\mathrm{R} \$ \\
374.874,75\end{array}$ & $\begin{array}{c}\mathrm{R} \$ \\
1.635 .276,24\end{array}$ & $\begin{array}{c}\mathrm{R} \$ \\
459.144,23\end{array}$ & $\begin{array}{c}\mathrm{R} \$ \\
256.751,49\end{array}$ \\
\hline 2009 & $\begin{array}{c}\mathrm{R} \$ \\
2.885 .248,74\end{array}$ & $\begin{array}{c}\mathrm{R} \$ \\
143.880,02\end{array}$ & $\begin{array}{c}\mathrm{R} \$ \\
391.192,44\end{array}$ & $\begin{array}{c}\mathrm{R} \$ \\
1.623 .445,19\end{array}$ & $\begin{array}{c}\mathrm{R} \$ \\
458.898,10\end{array}$ & $\begin{array}{c}\mathrm{R} \$ \\
267.832,98\end{array}$ \\
\hline 2010 & $\begin{array}{c}\mathrm{R} \$ \\
3.140 .078,38\end{array}$ & $\begin{array}{c}\mathrm{R} \$ \\
167.348,40\end{array}$ & $\begin{array}{c}\mathrm{R} \$ \\
422.439,85\end{array}$ & $\begin{array}{c}\mathrm{R} \$ \\
1.762 .414,38\end{array}$ & $\begin{array}{c}\mathrm{R} \$ \\
501.155,90\end{array}$ & $\begin{array}{c}\mathrm{R} \$ \\
286.719,86\end{array}$ \\
\hline 2011 & $\begin{array}{c}\mathrm{R} \$ \\
3.347 .905,45\end{array}$ & $\begin{array}{c}\mathrm{R} \$ \\
184.384,88\end{array}$ & $\begin{array}{c}\mathrm{R} \$ \\
446.307,19\end{array}$ & $\begin{array}{c}\mathrm{R} \$ \\
1.878 .474,24\end{array}$ & $\begin{array}{c}\mathrm{R} \$ \\
532.624,70\end{array}$ & $\begin{array}{c}\mathrm{R} \$ \\
306.114,44\end{array}$ \\
\hline 2012 & $\begin{array}{c}\mathrm{R} \$ \\
3.549 .399,19\end{array}$ & $\begin{array}{c}\mathrm{R} \$ \\
191.007,00\end{array}$ & $\begin{array}{c}\mathrm{R} \$ \\
481.435,50\end{array}$ & $\begin{array}{c}\mathrm{R} \$ \\
1.985 .294,38\end{array}$ & $\begin{array}{c}\mathrm{R} \$ \\
563.952,73\end{array}$ & $\begin{array}{c}\mathrm{R} \$ \\
327.709,59\end{array}$ \\
\hline 2013 & $\begin{array}{c}\mathrm{R} \$ \\
3.750 .435,39\end{array}$ & $\begin{array}{c}\mathrm{R} \$ \\
205.713,48\end{array}$ & $\begin{array}{c}\mathrm{R} \$ \\
509.653,76\end{array}$ & $\begin{array}{c}\mathrm{R} \$ \\
2.074 .242,92\end{array}$ & $\begin{array}{c}\mathrm{R} \$ \\
619.222,09\end{array}$ & $\begin{array}{c}\mathrm{R} \$ \\
341.603,14\end{array}$ \\
\hline 2014 & $\begin{array}{c}\mathrm{R} \$ \\
3.876 .930,62\end{array}$ & $\begin{array}{c}\mathrm{R} \$ \\
206.679,86\end{array}$ & $\begin{array}{c}\mathrm{R} \$ \\
540.117,47\end{array}$ & $\begin{array}{c}\mathrm{R} \$ \\
2.129 .807,24\end{array}$ & $\begin{array}{c}\mathrm{R} \$ \\
636.290,08\end{array}$ & $\begin{array}{c}\mathrm{R} \$ \\
364.035,98\end{array}$ \\
\hline 2015 & $\begin{array}{c}\mathrm{R} \$ \\
3.818 .243,01\end{array}$ & $\begin{array}{c}\mathrm{R} \$ \\
204.276,06\end{array}$ & $\begin{array}{c}\mathrm{R} \$ \\
540.363,68\end{array}$ & $\begin{array}{c}\mathrm{R} \$ \\
2.062 .482,62\end{array}$ & $\begin{array}{c}\mathrm{R} \$ \\
641.926,82\end{array}$ & $\begin{array}{c}\mathrm{R} \$ \\
369.193,82\end{array}$ \\
\hline Variação & $40,36 \%$ & $50,61 \%$ & $52,48 \%$ & $32,18 \%$ & $46,91 \%$ & $58,50 \%$ \\
\hline
\end{tabular}

Fonte: CAGED (2018).

Nota: Os valores foram deflacionados com base no ano de 2007.

Com base nos dados da Tabela 2, é possível perceber que o PIB per capita apresentou um aumento similar em todas as regiões brasileiras, sendo que o crescimento mais vigoroso foi apresentado pela região Nordeste, sendo seguida pelas Regiões Centro-Oeste e Sul. Cabe ressaltar, no entanto, que o PIB per capita nordestino continua sendo o menor do país, e passados os nove anos, seu valor é praticamente a metade do PIB per capita nacional. 
O maior PIB per capita dentre as grandes regiões continua sendo o do Sudeste, seguido pelo da região Centro-Oeste.

Tabela 2 - PIB Real Per Capita - Brasil e Grandes Regióes (Período de 2007 a 2015)

\begin{tabular}{|c|c|c|c|c|c|c|c|}
\hline Ano & & Brasil & Norte & Nordeste & Sudeste & Sul & Centro-Oeste \\
\hline 2007 & $\mathrm{R} \$$ & $14.465,00$ & $\begin{array}{c}\mathrm{R} \$ \\
9.135,00\end{array}$ & $\mathrm{R} \$ 6.749,00$ & $\begin{array}{c}\mathrm{R} \$ \\
19.277,00\end{array}$ & $\begin{array}{c}\mathrm{R} \$ \\
16.564,00\end{array}$ & $\begin{array}{c}\mathrm{R} \$ \\
17.844,00\end{array}$ \\
\hline 2008 & $\mathrm{R} \$$ & $14.760,45$ & $\begin{array}{c}\mathrm{R} \$ \\
9.430,44\end{array}$ & $\mathrm{R} \$ 6.912,21$ & $\begin{array}{c}\mathrm{R} \$ \\
19.554,14\end{array}$ & $\begin{array}{c}\mathrm{R} \$ \\
16.854,06\end{array}$ & $\begin{array}{c}\mathrm{R} \$ \\
18.805,50\end{array}$ \\
\hline 2009 & $\mathrm{R} \$$ & $14.645,08$ & $\begin{array}{c}\mathrm{R} \$ \\
9.097,99\end{array}$ & $\mathrm{R} \$ 7.025,62$ & $\begin{array}{c}\mathrm{R} \$ \\
19.310,94\end{array}$ & $\begin{array}{c}\mathrm{R} \$ \\
16.721,78\end{array}$ & $\begin{array}{c}\mathrm{R} \$ \\
19.277,18\end{array}$ \\
\hline 2010 & $\mathrm{R} \$$ & $16.062,22$ & $\begin{array}{c}\mathrm{R} \$ \\
10.327,27\end{array}$ & $\mathrm{R} \$ 7.750,30$ & $\begin{array}{c}\mathrm{R} \$ \\
21.389,90\end{array}$ & $\begin{array}{c}\mathrm{R} \$ \\
17.835,96\end{array}$ & $\begin{array}{c}\mathrm{R} \$ \\
20.060,61\end{array}$ \\
\hline 2011 & $\mathrm{R} \$$ & $16.949,97$ & $\begin{array}{c}\mathrm{R} \$ \\
11.197,22\end{array}$ & $\mathrm{R} \$ 8.121,18$ & $\begin{array}{c}\mathrm{R} \$ \\
22.581,85\end{array}$ & $\begin{array}{c}\mathrm{R} \$ \\
18.789,78\end{array}$ & $\begin{array}{c}\mathrm{R} \$ \\
21.060,28\end{array}$ \\
\hline 2012 & $\mathrm{R} \$$ & $17.781,79$ & $\begin{array}{c}\mathrm{R} \$ \\
12.838,19\end{array}$ & $\mathrm{R} \$ 8.681,90$ & $\begin{array}{c}\mathrm{R} \$ \\
23.638,78\end{array}$ & $\begin{array}{c}\mathrm{R} \$ \\
19.711,02\end{array}$ & $\begin{array}{c}\mathrm{R} \$ \\
22.171,03\end{array}$ \\
\hline 2013 & $\mathrm{R} \$$ & $18.602,98$ & $\begin{array}{c}\mathrm{R} \$ \\
12.108,19\end{array}$ & $\mathrm{R} \$ 9.112,97$ & $\begin{array}{c}\mathrm{R} \$ \\
24.472,43\end{array}$ & $\begin{array}{c}\mathrm{R} \$ \\
21.451,89\end{array}$ & $\begin{array}{c}\mathrm{R} \$ \\
23.090,88\end{array}$ \\
\hline 2014 & $\mathrm{R} \$$ & $19.119,98$ & $\begin{array}{c}\mathrm{R} \$ \\
11.994,63\end{array}$ & $\mathrm{R} \$ 9.612,99$ & $\begin{array}{c}\mathrm{R} \$ \\
25.022,52\end{array}$ & $\begin{array}{c}\mathrm{R} \$ \\
21.928,85\end{array}$ & $\begin{array}{c}\mathrm{R} \$ \\
23.918,88\end{array}$ \\
\hline 2015 & $\mathrm{R} \$$ & $18.672,68$ & $\begin{array}{c}\mathrm{R} \$ \\
11.669,95\end{array}$ & $\mathrm{R} \$ 9.553,73$ & $\begin{array}{c}\mathrm{R} \$ \\
24.053,53\end{array}$ & $\begin{array}{c}\mathrm{R} \$ \\
21.961,10\end{array}$ & $\begin{array}{c}\mathrm{R} \$ \\
23.908,06\end{array}$ \\
\hline Variação & & $29,09 \%$ & $27,75 \%$ & $41,56 \%$ & $24,78 \%$ & $32,58 \%$ & $33,98 \%$ \\
\hline
\end{tabular}

Fonte: CAGED (2018).

Nota: Os valores foram deflacionados com base no ano de 2007.

É possível perceber ainda, de acordo com Tabela 3, que o setor terciário apresentou o maior crescimento no número de postos de trabalho dentre os principais setores da economia brasileira, com destaque às regiões Norte e Nordeste do país que apresentaram respectivamente aumentos de $61,39 \%$ e $62,09 \%$ no número de postos formais de trabalho. A região Norte ainda apresenta o melhor desempenho no que se refere a geração de postos de trabalho também no setor primário, com uma variação positiva de $74,06 \%$ de enquanto a região Nordeste apresentou a segunda menor variação no crescimento do número de postos (10,36\%), estando a frente apenas da região Sul, que teve uma variação positiva de $7,74 \%$. No setor secundário, que abrange as atividades da indústria de transformação, construção civil e os setores de fornecimento de água e energia (combustíveis e eletricidade), ganham destaque as Regiões Centro-Oeste e a Nordeste que apresentaram durante o período crescimento respectivo de 30,67\% e 26,08\%. Surpreendentemente, na avaliação do setor secundário, a Região Sudeste, a mais industrializada do país, apresenta o pior desempenho dentre todas as macrorregiões brasileiras e apresentou no período uma variação positiva de $6,45 \%$ no número de postos de trabalho gerados. 
Tabela 3 - Variação do pessoal ocupado assalariado de unidades locais de empresas nos Grandes Setores no Brasil e nas Grandes Regiões (Período de 2007 a 2015)

\begin{tabular}{ccccccc}
\hline \multirow{2}{*}{ Brasil/Região } & \multicolumn{3}{c}{$\mathbf{2 0 0 7}$} & \multicolumn{3}{c}{$\mathbf{2 0 1 5}$} \\
\cline { 2 - 7 } & Primário & Secundário & Terciário & Primário & Secundário & Terciário \\
\hline Brasil & 647301 & 9071293 & 15657340 & 750402 & 10263206 & 22609785 \\
Norte & 31413 & 375918 & 643925 & 54678 & 440460 & 1039218 \\
Nordeste & 151795 & 1284731 & 2352118 & 167524 & 1619808 & 3812457 \\
Sudeste & 313330 & 4799745 & 8929391 & 347637 & 5109121 & 12184967 \\
Sul & 94450 & 2089221 & 2560926 & 101761 & 2412135 & 3729542 \\
Centro-Oeste & 56313 & 521678 & 1170980 & 78802 & 681682 & 1827886 \\
\hline
\end{tabular}

Fonte: IBGE (2018).

Para a análise da evolução dos indicadores de desenvolvimento socioeconômicos, optou-se pela utilização do IFDM. Foram analisadas as três dimensões do indicador (saúde, educação e emprego e renda) separadamente, com o objetivo de identificar como cada uma delas evoluiu ao longo do período analisado. No gráfico 1 é exposto o IFDM das grandes regiões brasileiras na dimensão saúde, obtido entre os anos de 2005 a 2016:

\section{Gráfico 1 -Variação no IFDM nas Regiões Brasileiras (2005-2016) - Dimensão} Saúde

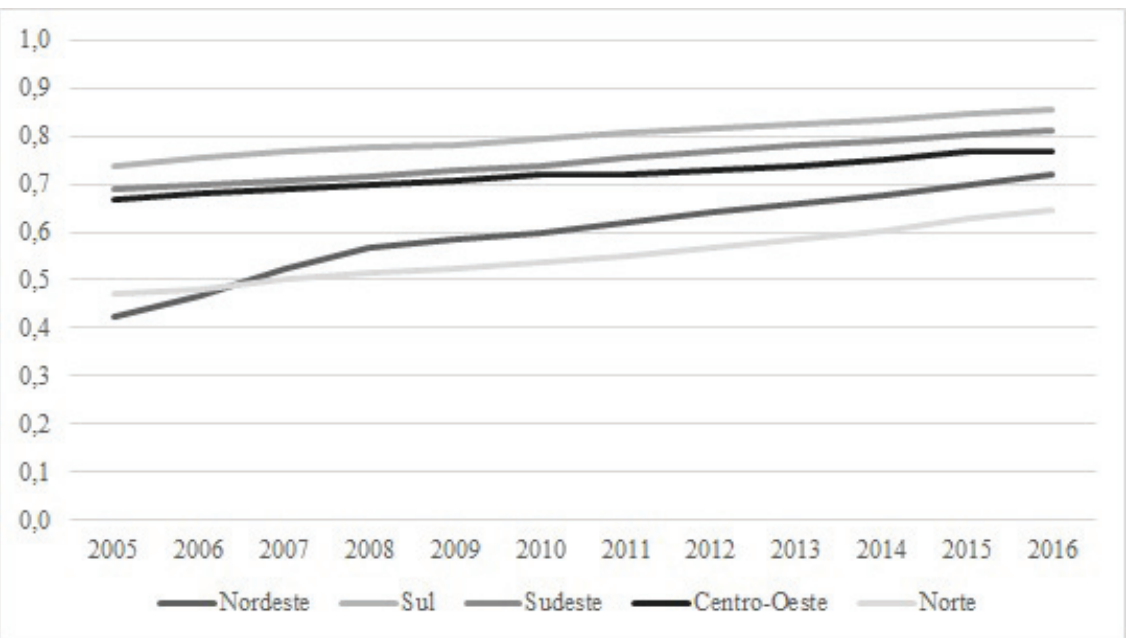

Fonte: FIRJAN (2018).

No gráfico 2 é exposto o IFDM das grandes regiões brasileiras na dimensão educação, também para o mesmo período (2005-2016): 


\section{Gráfico 2 - Variação no IFDM nas Regiões Brasileiras (2005-2016) - Dimensão Educação}

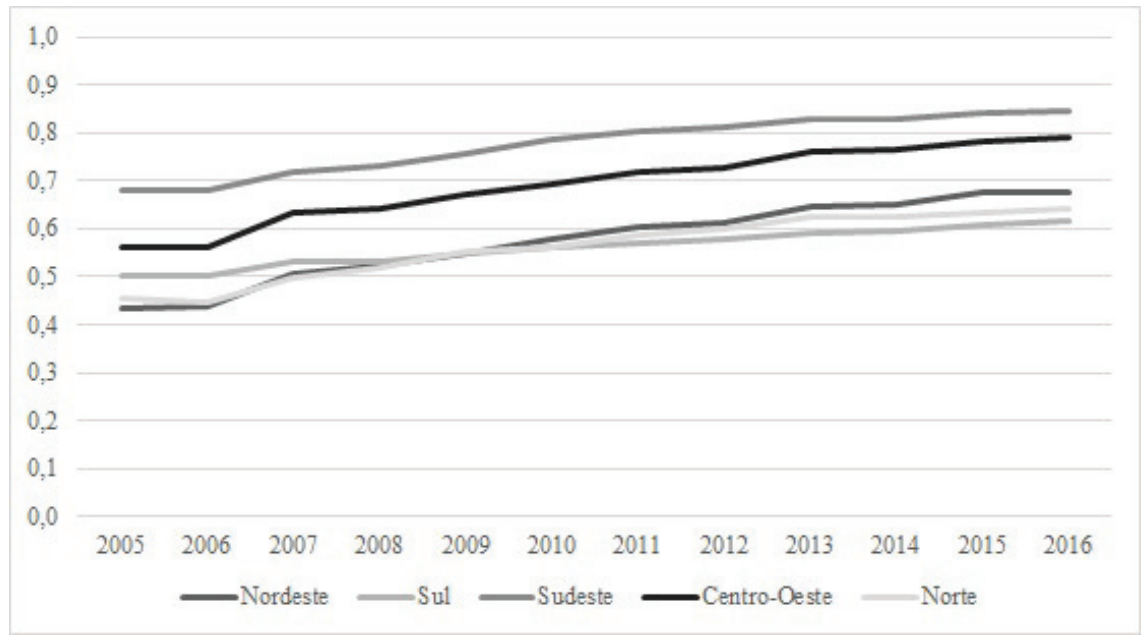

Fonte: FIRJAN (2018).

Percebe-se, a partir da análise dos Gráficos 1, 2, que as dimensões relacionadas a saúde e a educação, em todas as macrorregiões brasileiras, apresentaram melhorias durante o período analisado, tendo um crescimento mais acentuado entre os anos de 2005 a 2008. A Região Nordeste destaca-se como tendo o melhor desempenho em ambos os indicadores, apresentado pelas maiores variações positivas nos indicadores, apresentando na dimensão saúde um resultado duas vezes melhor do que a região Norte, que apresentou o segundo melhor desempenho.

A dimensão renda e emprego apresenta-se aqui como sendo a mais problemática. Não houve, como nas outras duas dimensões analisadas, o crescimento do índice referente a dimensão em nenhuma das regiões do país. A retração do índice indica a deterioração na geração de renda e a queda nos registros em postos de trabalho formais em todo o país. As regiões que apresentaram os piores desempenhos foram, respectivamente, as regiões Sudeste, Norte e Nordeste. No gráfico 3 é possível visualizar que os anos de 2008 e 2015 apresentaram maior declínio neste indicador, o que acredita se tratar dos efeitos causados pelas duas crises econômicas iniciadas nestes respectivos anos.

A Tabela 4 complementa a análise dos gráficos, ao apresentar a variação acumulada no período para o IFDM, considerando concomitantemente as três dimensões do indicador. Como se pode observar, os principais avanços ocorreram nas áreas de educação e saúde, destacando-se em nível nacional, em que pese. Releve-se, porém, que o período final de 2016 representa queda na dimensão emprego e renda em todo o país, sendo o Nordeste a terceira mais afetada das cinco grandes regiões. 
Gráfico 3 - Variação no IFDM nas Regiões Brasileiras (2005-2016) - Dimensão Emprego e Renda

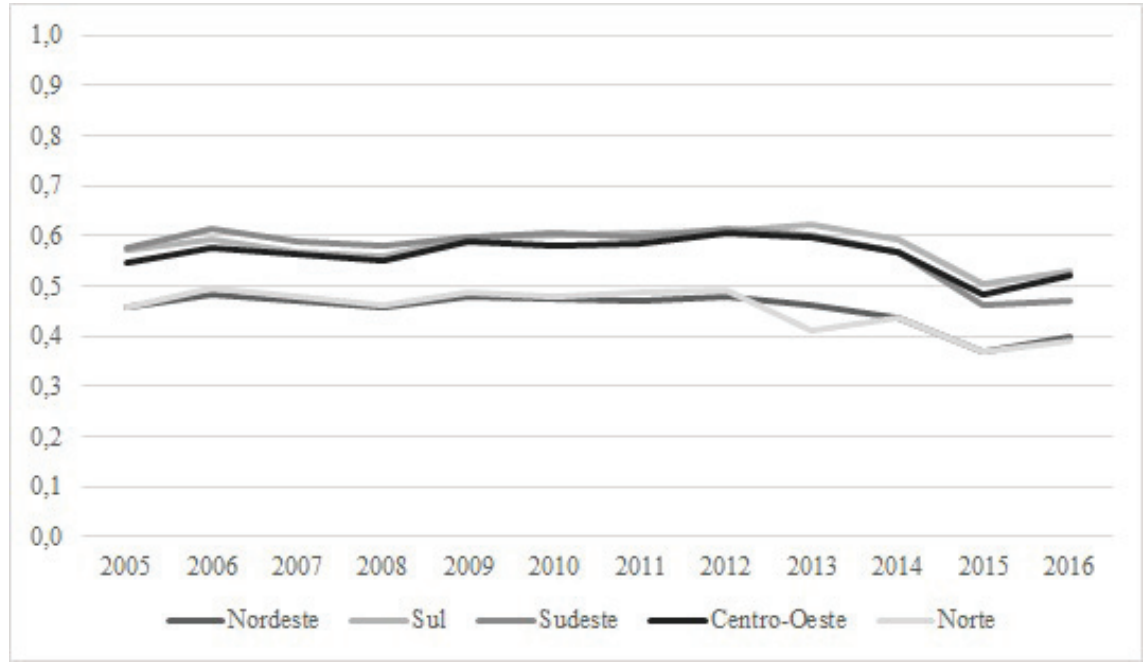

Fonte: FIRJAN (2018).

Tabela 4 - Variação nas Dimensões do IFDM nas Regiões Brasileiras (2005-2016)

\begin{tabular}{cccc}
\hline \multicolumn{4}{c}{ Variação nas Dimensões do IFDM } \\
\hline Região & Educação & Emprego e Renda & Saúde \\
\hline Nordeste & $55,71 \%$ & $-12,78 \%$ & $70,53 \%$ \\
Sul & $22,78 \%$ & $-6,92 \%$ & $15,63 \%$ \\
Sudeste & $23,83 \%$ & $-17,88 \%$ & $17,65 \%$ \\
Centro-Oeste & $40,60 \%$ & $-4,79 \%$ & $14,88 \%$ \\
Norte & $40,90 \%$ & $-14,76 \%$ & $37,18 \%$ \\
\hline
\end{tabular}

Fonte: FIRJAN (2018)

A tabela 5 apresenta a evolução do índice de Gini no Brasil e suas macrorregiões no período de 2006 a 2015. Segundo o IBGE (2018), o índice de Gini mede o grau de concentração de uma dada distribuição, variando de 0 (igualdade perfeita) a 1 (desigualdade máxima). A variável utilizada denominada "Índice Gini de distribuição do Produto Interno Bruto" mede o grau de concentração do PIB nos municípios, estados e regiões brasileiras. 
Tabela 5 - Índice de Gini da distribuição do produto interno bruto a preços correntes - Referência 2010.

\begin{tabular}{cccccccccccc}
\hline Brasil/Região & $\mathbf{2 0 0 6}$ & $\mathbf{2 0 0 7}$ & $\mathbf{2 0 0 8}$ & $\mathbf{2 0 0 9}$ & $\mathbf{2 0 1 0}$ & $\mathbf{2 0 1 1}$ & $\mathbf{2 0 1 2}$ & $\mathbf{2 0 1 3}$ & $\mathbf{2 0 1 4}$ & $\mathbf{2 0 1 5}$ & Variação \\
\hline Brasil & 0,865 & 0,865 & 0,863 & 0,863 & 0,864 & 0,862 & 0,861 & 0,857 & 0,856 & 0,853 & $-1,43 \%$ \\
Norte & 0,818 & 0,814 & 0,814 & 0,807 & 0,816 & 0,815 & 0,810 & 0,802 & 0,797 & 0,789 & $-3,48 \%$ \\
Nordeste & 0,798 & 0,799 & 0,796 & 0,798 & 0,803 & 0,799 & 0,804 & 0,801 & 0,798 & 0,794 & $-0,42 \%$ \\
Sudeste & 0,888 & 0,889 & 0,890 & 0,888 & 0,888 & 0,885 & 0,884 & 0,884 & 0,882 & 0,881 & $-0,74 \%$ \\
Sul & 0,791 & 0,789 & 0,783 & 0,789 & 0,791 & 0,788 & 0,792 & 0,778 & 0,781 & 0,779 & $-1,54 \%$ \\
Centro-Oeste & 0,858 & 0,852 & 0,848 & 0,852 & 0,854 & 0,847 & 0,842 & 0,838 & 0,841 & 0,840 & $-2,08 \%$ \\
\hline
\end{tabular}

Fonte: IBGE (2018).

É possível perceber que a desigualdade foi reduzida em todas as regiões brasileiras durante o período analisado, com maior destaque às Regiões Norte e Sul que apresentaram as maiores variações percentuais. A Região Nordeste, em contrapartida, foi a que apresentou os menores índices de diminuição nos níveis de desigualdade em relação a distribuição da renda per capita.

\section{Considerações finais}

Este artigo teve por objetivo realizar uma avaliação preliminar das contribuições da nova Sudene para o desenvolvimento do Nordeste do Brasil. A partir do método empregado e dos dados levantados, foi possível fazer uma análise exploratória das formas de atuação da nova Sudene e os avanços e limitações ao desenvolvimento socioeconômico do Nordeste no período de 2007 a 2017. Porém, as relações de causa-efeito entre os instrumentos de política da Sudene e seus resultados sobre o tecido produtivo ainda estão por ser investigadas.

Em relação a nova instituição legal da Sudene, dois pontos se destacam em relação à sua antecessora. O primeiro que, apesar de não mais vinculada diretamente à Presidência da República, o grau de autonomia e influência na formulação de política em âmbito do governo federal foi substancialmente ampliada, com destaque para a formulação do Plano Regional de Desenvolvimento do Nordeste, que é aprovado concomitantemente ao Plano Plurianual de cada mandato da Presidência da República, a fim de incluir nas leis orçamentárias as previsões de ação e de dotação de recurso para financiar as políticas de desenvolvimento regional. $\mathrm{O}$ segundo ponto refere-se à diretriz explícita de desenvolvimento sustentável, conceito este relacionado diretamente à sustentabilidade ambiental, tendo em vista a fragilidade do meio ambiente em grande parte do território de atuação da Sudene, incluindo-se aí a região semiárida e o cerrado.

Com forte apoio das instituições de fomento e de planejamento integrado com os governos de Estado, praticamente uma década depois 
foi possível observar importantes avanços socioeconômicos no Nordeste. O PIB per capita aumentou substancialmente no período, sendo possível observar ainda um movimento de fortalecimento da indústria da região. Porém, apesar disso, comparativamente à média nacional, a região ainda está muito aquém em termos da capacidade de geração de riqueza. Além disso, ainda é persistente a desigualdade, tendo sido o Nordeste a região que menos evoluiu no índice de Gini. Em termos de desenvolvimento socioeconômico, se nas áreas de geração de emprego e renda o desempenho é insatisfatório, por outro lado, destacaram-se as melhorias nos índices de saúde e de educação, o que pode refletir um fortalecimento do tecido produtivo e social futuramente.

Por fim, cabe ressaltar em que a recriação da Sudene nos moldes da Lei Complementar no 125/2007 representa um importante marco nas políticas públicas de desenvolvimento regional do Brasil, trazendo à tona a prática do planejamento econômico e da priorização da redução das disparidades regionais à União, como outrora fora idealizada, quando da criação da Sudene em 1959, durante o auge do planejamento econômico brasileiro, no governo Juscelino Kubitschek.

\section{Referências}

ARAÚJO. T. B. de. Por uma política nacional de desenvolvimento regional. Revista Econômica do Nordeste, Banco do Nordeste. Vol. 30, n.2 abr-jun de 1999. Disponível em: <http://www.fundaj.gov.br/index.php?option=com_conte nt\&view=article\&id=1958\%3 Apor-uma-politica-nacional-de-desenvolvimentoregional-\&catid=58\&Itemid=414>. Acesso em: 29 out. 2018.

BRASIL. Presidência da República. Lei n 3.692, de 15 de dezembro de 1959. Institui a Superintendência do Desenvolvimento do Nordeste e dá outras providências. Rio de Janeiro: 1959.

. Presidência da República. Lei Complementar no 125, de 03 de janeiro de 2007. Institui, na forma do art. 43 da Constituição Federal, a Superintendência do Desenvolvimento do Nordeste - SUDENE. Disponível em: <http://www. planalto.gov.br/ccivil_03/leis/lcp/Lcp125.htm>. Acesso em: 10 nov. 2018.

BRASIL, Superintendência de Desenvolvimento do Nordeste. Plano regional de Desenvolvimento do Nordeste. 2011.

BRASIL. Decreto n 6047, de 22 de fevereiro de 2007. Institui a Política Nacional de Desenvolvimento Regional - PNDR e dá outras providências. Disponível em: <http://www.planalto.gov.br/ccivil_03/_Ato2007-2010/2007/Decreto/D6047. htm>. Acesso em: 20 out. 2018.

DINIZ, C. C. Celso Furtado e o Desenvolvimento Regional. Nova Economia.: Belo Horizonte, v. 19, n. 2, p. 227-249, 2009. Disponível em: <http://www.scielo. br/scielo.php?script=sci_arttext\&pid=S0103-63512009000200001\&lng=en\&nrm $=$ iso $>$. Acesso em 16 de março de 2018. 
FEDERAÇÃO DAS INDÚSTRIAS DO ESTADO DO RIO DE JANEIRO. Índice Firjan de Desenvolvimento Municipal. Disponível em: <https://www. firjan.com.br/ifdm/>. Acesso em: 12 out. 2018.

IBGE - Instituto Brasileiro de Geografia e Estatística. Sistema IBGE de Recuperação Automática. Disponível em: <https://sidra.ibge.gov.br/home/pms/ brasil>. Acesso em: 10 out. 2018.

CARVALHO, F. F. A Extinção da Sudene: um marco das transformações na política de desenvolvimento regional no brasil. Orientador: Carlos Antonio Brandão, 2006. 247 f. Tese de Doutorado (Instituto de Economia) - Universidade Estadual de Campinas, Campinas, 2006.

CAVAlCANTE, L. R. Políticas de Desenvolvimento Regional no Brasil: uma estimativa de custos. Revista Brasileira de Gestão e Desenvolvimento Regional, v. 14, n. 3, 2018.

COSTA. M. R. da. O estado e a Sudene: Trajetória do Planejamento Regional no Brasil. 2016. Tese de Doutorado. Instituto de Filosofia e Ciências Humanas. Universidade Estadual de Campinas. Campinas - SP.

DYE, T. R. Understanding Public Policy. 13 ed. USA: Pearson Education, 2011.

FURTADO, C. A Operação Nordeste. Rio de Janeiro: Instituto Superior de Estudos Brasileiros, 1959a. $1959 \mathrm{~b}$.

Formação Econômica do Brasil. Rio de Janeiro: Fundo de Cultura,

Raízes do Subdesenvolvimento. $3^{a}$ ed. Rio de Janeiro: Civilização Brasileira, 2014.

GUMIERO, R. G. A trajetória das políticas de desenvolvimento regional do Nordeste: balanço entre a Operação Nordeste e a PNDR. Revista Política e Planejamento Regional, v. 4, n. 2, p. 189-210, 2017.

IBGE - Instituto Brasileiro de Geografia e Estatística. Conceitos. Disponível no link: <https://ww2.ibge.gov.br/home/estatistica/populacao/condicaodevida/ indicadoresminimos/conceitos.shtm>. Acesso em: 30 nov. 2018.

KRAFT,M.E.; FURLONG, S. R.Public Policy: politics, analysis and alternatives. 3a. ed. USA: CQ Press, 2010.

MASCARENHAS, L.; LOURENÇO NETO, S. Superintendência Do Desenvolvimento do Nordeste (Sudene). FGV CPDOC: Rio de janeiro, [s.d.]. Disponível em: <http://www.fgv.br/cpdoc/acervo/dicionarios/verbete-tematico/ superintendencia-do-desenvolvimento-do- Nordeste-Sudene>. Acesso em: 28 mar. 2018.

MENDES, F. S. No Olho do Furacão: Celso Furtado e Francisco de Oliveira nos Primeiros Anos da Sudene. Lua Nova, São Paulo, n. 100, p. 283-311, jan. 2017. Disponível em: <http://www.scielo.br/scielo.php?script=sci_arttext\&pid=S010264452017000100283\&lng=pt\&nrm=iso >. acesso em: 29 de março de 2018.

MOREIRA, C. C. P. A extinção da Sudam e da Sudene. Revista de Informação Legislativa, Brasília. v. 40, n. 157, jan-mar. 2003. Disponível em: <http://www. senado.gov.br/web/cegraf/ril/Pdf/pdf_157/RIL157-10.pdf> Acesso em: 18 de maio de 2018. 
OLIVEIRA, R. V. Trabalho no Nordeste em Perspectiva Histórica. Estud. Av, São Paulo, v. 30, n. 87, p. 49-73, Ag. 2016. Disponível em: < http://www.scielo.br/ scielo.php?script=sci_arttext\&pid=S0103-40142016000200049\&lng=en\&nrm=i so>. Acesso em: 29 de março 2018.

PINDER, D. Regional economic development and policy: Theory and practice in the European Community. Routledge, 2017.

SILVA, A. M. A.; ALMEIDA, M. Desafios de Uma Nova Política Regional para o Nordeste. Boletim Regional, Urbano e Ambiental. Ipea, jun. 2011. Disponível em: <http://repositorio.ipea.gov.br/bitstream/11058/5625/1/BRU_n5_desafios. pdf> Acesso em: 23 mai. 2018.

SILVA FILHO, L. A. da. Recriação da Sudene: Retrato de Uma Luta. Recife: INAD. 2008. Disponível em: <www.inad.com.br/publicacao/ arquivos/20120730144000p_MANO_FINAL_2ed.pdf>. Acesso em: 21 mai. 2018.

SOUSA, C. de. Instituições, Políticas Públicas e Planejamento para o Desenvolvimento da Região Nordeste do Brasil. Orientador: Henrique Tomé da Costa Mata, 2008. 120 f. Dissertação de Mestrado (Mestrado em Economia) Universidade Federal da Bahia, Salvador, 2008.

SOUZA, C. Políticas Públicas: uma revisão da literatura. Sociologias, Porto Alegre, ano 8, no 16, p. 368-375, jul./dez 2006.

SUDENE. Disponível em: <http://www.sudene.gov.br>. Acesso em: 18 out. 2018.

Fundo de Desenvolvimento do Nordeste. Disponível em: <http://www. sudene.gov.br/fundo-de-desenvolvimento-do-nordeste-fdne>. Acesso em: 20 out. 2018.

TORRES, R.; GOMES, C. P.; BEATRICE, F. O.; CALDERARI, E. B. Evolução institucional da Sudene: gênese, extinção e recriação. Revista Política e Planejamento Regional, Rio de Janeiro, v. 6, n. 2, p. 164-182, mai-ago, 2019.

Submetido em: 31/05/2019.

Aceito em: 16/10/2019. 


\title{
NEW SUDENE'S CONTRIBUTIONS TO NORTHEAST DEVELOPMENT
}

\begin{abstract}
This paper makes a preliminary assessment of the contributions of the new Sudene to the development of the Northeast, based on the political guidelines established from its re-creation in 2007. For the study, bibliographic and documentary research was conducted to map the guidelines and Sudene's priorities. A survey of secondary statistical data was also performed to analyze the socioeconomic evolution of the Northeast from 2007 to 2017. For this, was used the data of GDP, GDP per capita and Gini index of IBGE, and the development index. municipal human body of Firjan. Survey results indicate that Sudene has regained its strategic importance in federal government policy, as demonstrated by the legal institution of the alignment of the Northeast Regional Development Plan with the Multiannual Plan, with participation in the preparation of the Union budget, to ensure resources for the region's development. After a decade of its recreation, it is possible to see socioeconomic advances, such as the highest growth of GDP per capita in the country, of $41.5 \%$ between 2007 and 2015, while the national average was 29\%. There was a significant improvement in the human development index in the health and education dimensions, accumulating in the period a variation of $55.7 \%$ and $70.5 \%$, respectively. However, the limitations of this progress are still noteworthy, since GDP per capita is still almost half of the national average and the Northeast still has the highest income inequality index in the country.
\end{abstract}

Keywords: Sudene. Northeast. Regional development. Economic planning. Public policy.

\section{NUEVAS CONTRIBUCIONES DE SUDENE AL DESARROLLO DEL NORESTE}

\begin{abstract}
Resumen
Este documento realiza una evaluación preliminar de las contribuciones de la nueva Sudene al desarrollo del Nordeste, con base en las pautas políticas establecidas desde su recreación en 2007. Para el estudio, se realizó una investigación bibliográfica y documental para mapear las pautas. y prioridades de Sudene. También se realizó una encuesta de datos estadísticos secundarios para analizar la evolución socioeconómica del Nordeste de 2007 a 2017. Para ello, utilizamos los datos del PIB, el PIB per cápita y el índice de Gini del IBGE, y el índice de desarrollo. Cuerpo humano municipal de Firjan. Los resultados de la encuesta indican que Sudene ha recuperado su importancia estratégica en la política del gobierno federal, como lo demuestra la institución legal de la alineación del Plan de Desarrollo Regional del Noreste con el Plan Plurianual, con participación en la preparación del presupuesto de la Unión, para garantizar recursos para el desarrollo de la región. Después de una década de recreación, es posible ver avances socioeconómicos, como el mayor crecimiento del PIB per cápita en el país, del 41,5\% entre 2007 y 2015, mientras que el promedio nacional fue del 29\%. Hubo una mejora significativa en el índice de desarrollo humano en las dimensiones de salud y educación, acumulando en el período una variación de $55.7 \%$ y 70.5\%, respectivamente. Sin embargo, las limitaciones de este progreso aún son notables, ya que el PIB per cápita sigue siendo casi la mitad del promedio nacional y el noreste aún tiene el índice de desigualdad de ingresos más alto del país.
\end{abstract}

Palabras clave: Sudene. Noreste. Desarrollo regional. Planificación económica. Políticas públicas. 